\title{
Septic arthritis of the sacroiliac joint
}

\author{
Patryk J. Woytala ${ }^{1}$, Agata Sebastian ${ }^{1}$, Katarzyna Błach ${ }^{2}$, Jurand Silicki ${ }^{3}$, Piotr Wiland ${ }^{1}$ \\ ${ }^{1}$ Department of Rheumatology and Internal Medicine, Wroclaw Medical Hospital, Poland \\ ${ }^{2}$ VI Department of Internal Diseases, Rheumatology and Geriatrics, Provincial Specialist Hospital J. Gromkowskiego, Wroclaw, Poland \\ ${ }^{3}$ Department of General and Paediatric Radiology, Wroclaw Medical University, Poland
}

\begin{abstract}
Septic arthritis is an inflammation of a joint caused directly by various microorganisms. It is often characterized by many unspecific symptoms. Bacteria is the most often etiological factor. We present a case report of a 76-years old woman with a unilateral septic arthritis of the sacroiliac joint. Bacterial sacroiliitis should be taken into account in patients with sacroiliitis and fever onset. Proper diagnosis can be very often difficult and delayed but fast implementation of antibiotic therapy is extremely important in the treatment process. Diagnostic imaging is crucial to the diagnosis and monitoring of septic arthritis. Magnetic resonance imaging is the most relevant tool for the detection of sacroiliitis, allowing the institution of therapeutic strategies to impede the progression of the disease.
\end{abstract}

Key words: infectious arthritis, septic arthritis, sacroiliitis, Staphylococcus aureus.

\section{Introduction}

Septic arthritis (SA) is an inflammation of a joint caused directly by various microorganisms. Bacteria is the most often etiological factor (> 95\% of all infections). Fungus or parasites can also cause this infection but it occurs very sporadically. Septic arthritis has an important clinical significance, as it is characterized by rapid destruction of the affected joint and is associated with significant morbidity and mortality.

Septic arthritis is a rare disease with a prevalence of 2-5/100 000 people per year in the general population. However, this rate is higher in the pediatric population (5.5$12 / 100000$ per year) or in patients with RA (28-38/100 000 per year),in patients with endoprosthetic joints (40-68/ 100000 per year) [1, 2].

The most important risk factors are chronic diseases (like diabetes type II, rheumatoid arthritis), joint replacement surgery, drugs which are administrated intraarticular or in the vicinity of joints, immune deficiency diseases (HIV, AIDS) or immunosuppressive therapy, drugs or alcohol addictions, age over 80 years, haemophilia, cancer, chronic liver or kidney disease (renal failure, dialysis), other infections (skin, previous joint or urinary tract infection).
Septic arthritis can be either one-or polyarticular. In most cases it undergoes as an acute, destructive arthritis. The infection is spreading in $90 \%$ of cases by blood. Septic arthritis is one of the so-called "acute conditions" in rheumatology.

\section{Case report}

A 76-year-old woman applied at the Department of Internal Medicine because of the persistent fever $\left(38.8^{\circ} \mathrm{C}\right.$ for approximately 4 weeks), constant feeling of tiredness, periodically occurring non-specific headache and severe pain in the right lumbosacral region radiating to the right lower extremity which occurred at rest and intensified when moving. In the medical history the patient reported that she suffers from diabetes type 2 (metformin $850 \mathrm{mg}$ once daily), hypertension (ramipril $10 \mathrm{mg}$ once daily, hydrochlorothiazide $12.5 \mathrm{mg}$ once daily), hyperlipidemia (rosuvastatin $10 \mathrm{mg}$ once daily) and hypothyroidism (levothyroxine $75 \mu \mathrm{g}$ once daily).

In the laboratory tests were found following disorders: leukocytosis $17.7 \times 10^{9} / \mathrm{l}$, anemia (hemoglobin $8.4 \mathrm{~g} / \mathrm{dl})$ and CRP $265 \mathrm{mg} / \mathrm{l}(n<5 \mathrm{mg} / \mathrm{l})$. Blood and urine cultures were sterile. 
In lumbar spine magnetic resonance (MRI) degenerative changes with multilevel discopathy were noted. The patient was consulted by a neurologist and a specialist of infectious diseases. In the treatment empirical antibiotic (ciprofloxin $200 \mathrm{mg}$ i.v. twice daily and amoxicillin 1000 mg p.o. twice daily) and non-steroidal anti-inflammatory drugs ware administered. As a result of this therapy the patient's general condition had improved (a decrease of fever and lumbosacral pain relief).

There was no basis for the diagnosis of inflammatory spondyloarthropathy or rheumatoid arthritis. The recurrence of the described symptoms occurred about two months later.

The patient applied at the Department of Rheumatology and Internal Diseases. Physical examination showed the following disorders: fever $\left(39^{\circ} \mathrm{C}\right)$, limitation of motion of the hip joints, knee joints and lumbosacral spine, painfulness compression of the L4-S1 segment of the spine, which was more perceptible on the right side of the spine and on the right buttock. No pathological changes of the skin or muscles were noticed. Lymph nodes were not palpable.

The laboratory tests performed have shown a leukocytosis $13.98 \times 10^{9} / \mathrm{l}$ (nv 4-10) with neutrophils 10.72 $\times 10^{9} / /(\mathrm{nv} 2.5-6.0)$, erythrocytes $3.13 \times 10^{12} / /(\mathrm{nv} 4-5)$, hemoglobin $8.4 \mathrm{~g} / \mathrm{dl}$ (nv 12-16), hematocrit 26.7\% (nv 37-47), platelets $560 \times 10^{9} / \mathrm{l}$ (nv 140-440), hypoalbuminemia [albumin $3.2 \mathrm{~g} / \mathrm{dl}$ (nv 4.3-5.1), 42.7\% (nv 6071)], hypergammaglobulinemia [gamma globulin $1.5 \mathrm{~g} /$ dl (nv 0.6-1.2), 20.3\% (nv 8-16)], ESR 121 mm (nv 3-15), ultra-sensitive CRP $181.98 \mathrm{mg} / \mathrm{l}$ (nv 0-5), fibrinogenactivity > $9.10 \mathrm{~g} / \mathrm{l}$ (nv 1.8-3.5), procalcitonin $0.06 \mathrm{ng} / \mathrm{ml}$

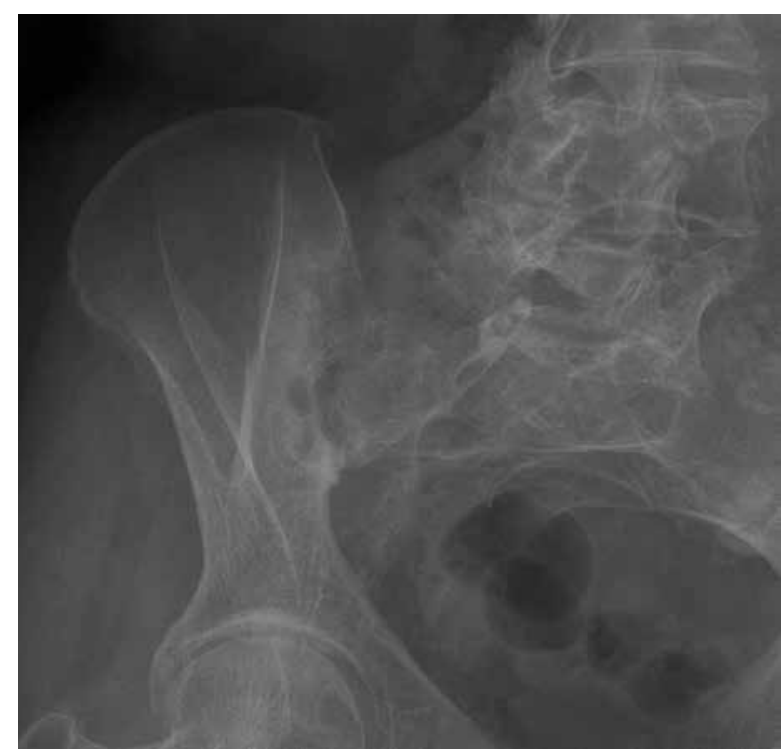

Fig. 1. The X-ray image of the right sacroiliac joint of the patient. (nv 0-0.05). All other parameters like fasting glycaemia, transaminases, creatinine, eGFR, electrolytes, APTT, INR, TSH or tumor markers were normal. Occult blood fecal analysis (chromatography) for 3 consecutive days did not showed any abnormalities. In several times made urine analysis characterizing bacteriuria was found, but the urine culture was negative. X-ray of the chest was normal. USG of the abdominal cavity revealed widening of the renal pelvis in the left kidney.Based on the echocardiography mitral regurgitation without hemodynamic significance was found (EF: 67\%). The myelogram showed hyperplasiaof the bone marrow granulocytic component (76.4\%), mainly of the older form - of segmented kernel. The morphological characteristics of cells were without significant disorders.

The X-ray and the USG of the hip joints illustrated significant degenerative changes. In the $X$-ray of the sacroiliac joints a mixed but unspecific picture of the right sacroiliac joint was found (Fig. 1). Because of this further MRI was arranged. The MRI image of the sacroiliac joints has shown extensive, stalactite inflammation of the right sacroiliac joint with the infiltration of the muscles (Figs. 2, 3). There were also visible small abscesses in the right piriformis muscle and invasion of sacral canal spinal stenosis on the level of L4/L5. In addition, the twice made blood culture was positive and Staphylococcus aureus methicillin sensitive (MSSA) had been isolated. The patient was diagnosed with sacroiliac joint inflammation of infectious etiology (Staphylococcus aureus). It was the reason for starting antibiotic therapy according to the antibiogram: cefuroxime $3 \times 750 \mathrm{mg}$ i.v. (used for ten weeks in total)

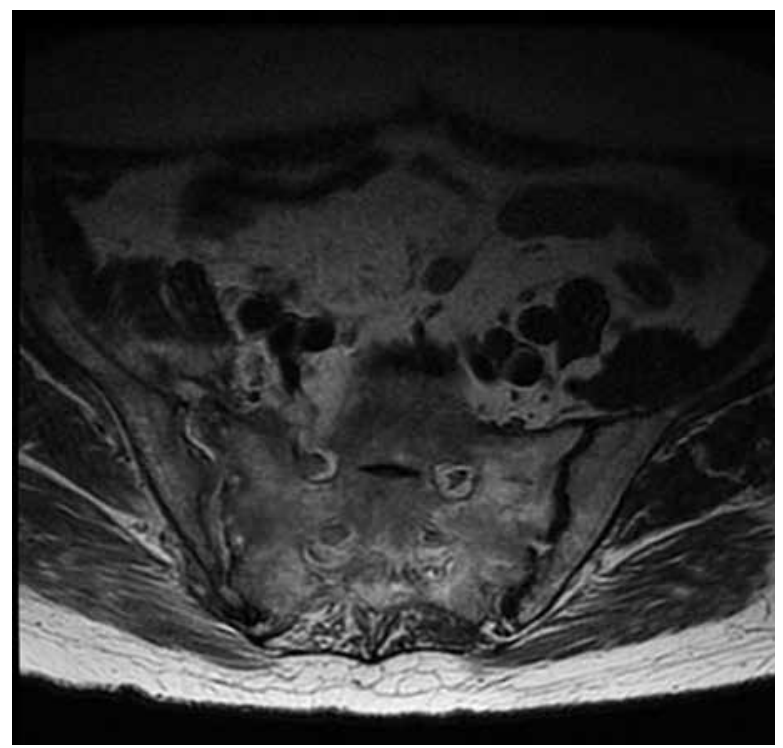

Fig. 2. The MRI sacroiliac joints of the patient at diagnosis. 


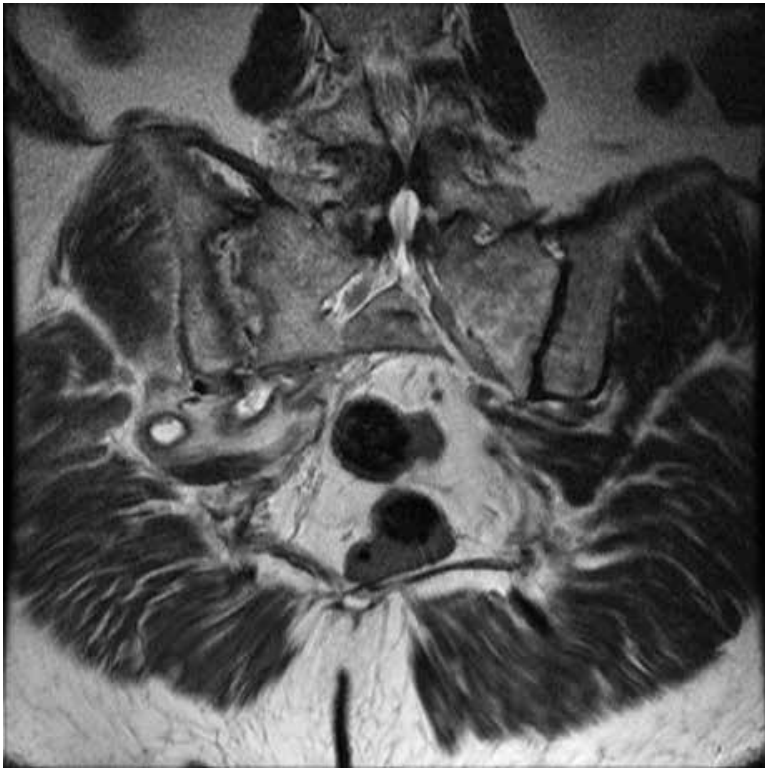

Fig. 3. The MRI sacroiliac joints of the patient at diagnosis.

and ciprofloxacin i.v. $2 \times 200 \mathrm{mg}$ (for four weeks in total). Then, clindamycin $3 \times 300 \mathrm{mg}$ i.v. (for eight weeks in total) and after the patient has being discharged from the hospital clindamycin $3 \times 300 \mathrm{mg}$ p.o. (for other eight weeks).

Due to the spinal stenosis the patient was also consulted by a neurosurgeon and due to a slight widening of the renal pelvis of the left kidney the patient was consulted by a nephrologist and urologist in order to find a primary outbreak of the infection. But there had not been stated any association with urinary system. Two months after the start of antibiotic therapy the control CT of sacroiliac joints was performed. In this image the regression of all the pathological changes was observed (Fig. 4).

After five months of antibiotic therapy a relief of pain and fever had been achieved, the laboratory parameters had normalized (leukocytes $8 \times 10^{9} /$, CRP $5 \mathrm{mg} / \mathrm{l}$ ) and the patient had been discharged from the hospital. After six and after nine months after diagnosis the control MRI of the sacroiliac joints was performed. Their images showed further regression of the pathological changes. The patient is now being under the control of a rheumatologist and a neurosurgeon. Due to lasting back pain there are also plans for orthopedic surgery of the right sacroiliac joint.

\section{Discussion}

Bacterial infection is one of the most serious causes of arthritis. Septic arthritis of the sacroiliac joints is very rare - about $1-2 \%$ of all septic arthritis can affect the sacroiliac joints. Despite the presence of characteristic symptoms the proper diagnosis can be very often diffi-

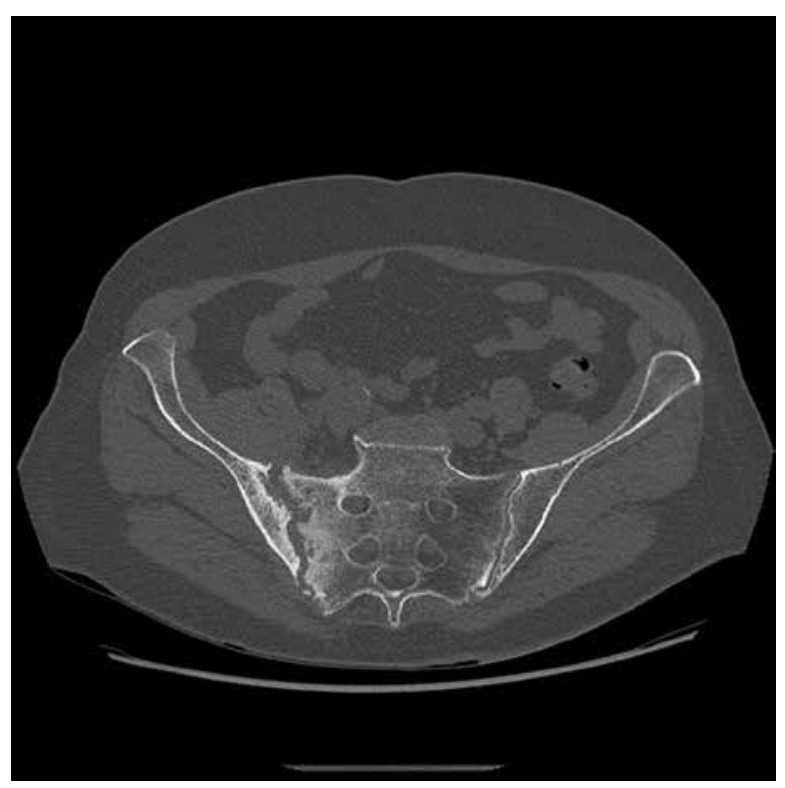

Fig. 4. Control image of the sacroiliac joints after two months after the start of antibiotic therapy.

cult and delayed [2, 3]. Bacterial sacroiliac joints inflammation is often mistaken during the initial period with sciatica, spondylodiscitis, chronic pain syndrome of the lumbar spine or even spondyloarthropathy $[2,4]$.

In the most cases it is connected with pain of large degree. This pain is very often localized around the lumbar-buttock $[2,5,6]$.One-sided form occurs most often, however there is literature described cases of both sides sacroiliac joints [7].

For diagnosis of septic arthritis microbiological analysis and testing for antibiotic sensitivity of the synovial fluid of a suspected septic joint is required [8]. In the described case the septic inflammation of the sacroiliac joint was diagnosed based on the twice performed positive blood culture test, changes in the sacroiliac joints and surrounding tissues imaged in MRI and based on the specific clinical symptoms $[9,10]$. Due to a quick response to the antibiotics used (major decrease in CRP, relief of fever) in our casethe joint puncture was not conducted.

The most common pathogen which causes septic arthritis (including the sacroiliac joints) is Staphylococcus aureus [6, 11-14], but there are described cases of other pathogens like Salmonella spp., Brucella spp., Streptococcus pyogenes [15-18].

Fast diagnosis and the implementation of antibiotic therapy isextremely important in the treatment process for this disease. Not treated septic arthritis leads to serious complications such as sepsis, abscess formation or infection of other organs, including the vegetations on the endoprosthesis $[10,14,18,19]$. 
The rapid implementation of antibiotic treatment gives good prognosis for this disease. Most authors describe the patients' condition improvement after 4-5 weeks of the intravenous antibiotic therapy. However, there is the need of the further studies on this disease in order to establish long-term monitoring scheme $[2,5,20-22]$. It is also worth to seek out new therapeutical schemes which would shorten the infection duration or to study new antibiotics which are effective against staphylococci like linezolid or daptomycin [23-25].

In the described case extensive diagnostic tests were performed. To locate the source of Staphylococcus aureus infection following factors were taken into account: the initial infection of the urinary tract, intramuscular injections lumbar and gluteal area or tooth infection [26]. Despite this we did not manage to locate the source of Staphylococcus aureus infection. One of the rare causes of infectious sacroiliac joint is an infection by the lumbar anaesthesia before birth [27]. In addition, tests performed excluded the possibility for another spot of Staphylococcus aureus infection besides right sacroiliac joint.

When monitoring the regression of the disease we decided to use MRI - like most authors, because MRI signal abnormalities in the joints occupied persist even months after the relief of clinical symptoms [28, 29].

Due to the risk of severe complications infective sacroiliac joint is an important clinical state that requires urgent diagnosis and rapid implementation of the treatment.

The authors declare no conflict of interest.

\section{References}

1. Kherani R, Shojania K. Septicarthritis in patients with pre-existing inflammatory arthritis. CMAJ 2007; 176: 1605-1608.

2. Hermet M, Minichiello E, Flipo RM, et al. Infectious sacroiliitis: a retrospective, multicentre study of 39 adults. BMC Infectious Diseases 2012; 12: 305.

3. Margaretten ME, Kohlwes J, Moore D, Bent S. Does this adult patient have septic arthritis? JAMA 2007; 297: 1478-1488.

4. Gouliouris T, Aliyu SH, Brown NM. Spondylodiscitis: update on diagnosis and management. J Antimicrob Chemother 2010; 65: 11-24.

5. Zimmerman B III, Mikolich D, Lally E. Septic sacroiliitis. Semin Arthritis Rheum 1996; 26: 592-604.

6. Vyskocil J, Mcllroy M, Brennan T, Wilson FM. Pyogenic infection of the sacroiliac joint. Case reports and review of the literature. Medicine (Baltimore) 1991; 70: 188-197.

7. Oka M, Möttönen T. Septic sacroiliitis. J Rheumatol 1983; 10: 475478.

8. Mathews CJ, Coakley G. Septic arthritis: current diagnostic and therapeutic algorithm. Curr Opin Rheumatol 2008; 20: 457-462.

9. Braun J, Sieper J, Bollow M. Imaging of sacroiliitis. Clin Rheumatol 2000; 19: 51-57.
10. Kucera T, Brtkova J, Sponer P, et al. Pyogenic sacroiliitis: diagnosis, management and clinical outcome. Skeletal Radiol 2015; 44: 63-71.

11. Dubost J, Soubrier M, De Champs C, et al. No changes in the distribution of organisms responsible for septicarthritis over a 20 year period. Ann Rheum Dis 2002; 61: 267-269.

12. Anolik J, Wildy K, Cohn SE, et al. Multifocal Staphylococcus aureus infection originating from the sacroiliac joint in a patient with rheumatoid arthritis. J Rheumatol 2001; 28: 217-220.

13. Shanahan MD, Ackroyd CE. Pyogenic infection of the sacroiliac joint. A report of 11 cases. J Bone Joint Surg Br 1985; 67: 605-608.

14. Chebbi W, Jerbi S, Kessomtini W, et al. Pyogenic sacroiliitis and pyomyositis in a patient with systemic lupus erythematous. Case Rep Rheumatol 2014; 2014: ID 925961.

15. Wu M, Chang S, Lee S, Lee C. Pyogenic sacroiliitis - a comparison between paediatric and adult patients. Rheumatology (Oxford) 2007; 46: 1684-1687.

16. Govender S, Chotai PR. Salmonella osteitis and septic arthritis. J Bone Joint Surg Br 1990; 72: 504-506.

17. Gheita TA, Sayed S, Azkalany GS, et al. Subclinical sacroiliitis in brucellosis : Clinical presentation and MRI findings. Z Rheumatol 2015; 74: 240-245.

18. Mahfoudhi M, Hariz A, Turki S, Kheder A. Septic sacroiliitis revealing an infectious endocarditis. BMJ Case Rep 2014; 2014. pii: bcr2014204260.

19. Abbot AE, Sculco T. Septic sacroiliitis with hematogenous spread to a total knee arthroplasty. J Arthroplasty 2001; 16: 225-228.

20. Osman A, Govender S. Septic sacroiliitis. Clin Orthop Relat Res 1995; 313: 214-219.

21. Roblot F, Besnier JM, Juhel L, et al. Optimal duration of antibiotic therapy in vertebral osteomyelitis. Semin Arthritis Rheum 2007; 36: 269-277.

22. Bindal M, Krabak B. Acute bacterial sacroiliitis in an adult: a case report and review of the literature. Arch Phys Med Rehabil 2007; 88: 1357-1359.

23. Rayner C, Baddour L, Birmingham M, et al. Linezolid in the treatment of osteomyelitis: results of compassionate use experience. Infection 2004; 32: 8-14.

24. Falagas ME, Giannopoulou KP, Ntziora F, et al. Daptomycin for treatment of patients with bone and joint infections: a systematic review of the clinical evidence. Int I Antimicrob Agents 2007; 30: 202-209.

25. Licitra C, Crespo A, Licitra D, Wallis-Crespo M. Daptomycin for the Treatment of Osteomyelitis and Prosthetic Joint Infection: Retrospective Analysis of Efficacy and Safety in an Outpatient Infusion Center. Internet J Infect Dis 2010; 9: no 2.

26. Edelstein $\mathrm{S}$, Edoute $\mathrm{Y}$. Bacterial sacroiliitis probably induced by lumbar epidural analgesia. Infect Dis Obstet Gynecol 2003; 11: 105-108.

27. Mulvey JM. Postpartum septic sacroiliitis coincident with labour epidural analgesia. Anaesth Intensive Care 2008; 36: 875-878.

28. Stürzenbecher A, Braun J, Paris S, et al. MR imaging of septic sacroiliitis. Skeletal Radiol 2000; 29: 439-446.

29. Blum U, Buitrago-Tellez C, Mundinger A, et al. Magnetic resonance imaging for detection of active sacroiliitis - a prospective study comparing conventional radiography, scintigraphy, and contrast-enhanced MRI. J Rheumatol 1996; 23: 2107-2115. 